\title{
Contents, Vol. 32, 1914
}

Inhalts-Verzeichnis.

Original-Arbeiten. Seite

Barth, Th., Untersuchungen über Häufigkeit und Lokálisationvon beginnenden Linsentrübungen bei 302 über 60 Jahrealten Personen 8, 143

Bergmeister, Rud., Ruptur der M. descemeti mit partieller

Nekrose der Hornhaut im Gliomauge. (Hierzu Taf. II) $20 \delta$

Cords, Rich., Bemerkungen zur Untersuchung des Tiefen-schätzungsvermögens. III. Die

Verwertung der parallakti-schen Verschiebung durch Einäugige 34

Dutoit, A., Augenstörungen bei einem Fall von Myxödem . 139

, Beobachtung eines Falles mit Keratitis neuroparalytica

infolge einer Alkoholinjektion in den Nervus maxillarissuperior bei Gesichtsneuralgie $\quad 26$

Eppenstein, A., Ziir Kenntnis der Lidnekrosen. (Hierzu Taf. I) 16

Erdmann, P., Ueber die Wirkung fortgesetzter subkonjunkti-valer Injektionen von

Nebennierenpräparaten beimKaninchen und ihre therapeutische Verwendung beimMenschen 216

Foroni, C, Ein neues Verfahren zur Behandlung der Dakryo-

cystitis. (Hierzu Taf. Ill) 226

Gebb, H., Chemotherapie in der Augenheilkunde mit Ausschluß

des Salvarsans 265

Jampolshy, Fanny, Sympathische Ophthalmie nach der

Enukleation 233

Kirsch, R., Anatomische Untersuchung eines Falles von Cilie

in der Vorderkammer. (Hierzu Taf. V) 426

Kuhnt, H., Ueber die Behandlung der Fistula cornea . . . 421

Lauber, H., Drei merkwürdige Fäl·le von Augenverletzungen.

(Hierzu Taf. IV) 360

Ohm, Joh., Zur graphischen Registrierung des Augenzitterns

der Bergleute und der Lidbewegungen 4

Perlmann, A., Ueber die Gewöhnung an die Einäugigkeit und

ihren Nachweis $\quad 107,244$

, 1st der völlige Verlust eines Auges höher zu entschädigen

als die bloße Erblindung ? 431

Schieck, Kann die Keratitis parenchymatosa auf anaphylakti-

schen Zuständen beruhen ? 95

Stuelp, 0., Ueber den ursächlichen Zusammenhang chronischer Augenerkrankungen mit dem sogenannten , ,chronischen” Gelenkrheumatismus, insbesondere mit der chronischen progressiven Polyarthritis ankylosans et deformans 341, 435

Ticho, Ueber Trachombehandlung in den Schulen 368

Trappe, E., Sogenannte Embolie einer cüioretinalen Arterie 124 
Wolff, Hugo, Zur Skiaskopie mit der Gullstrandschen Nernstspaltlampe und unfoliierter Glasplatte 1

- IV -

Seite

Berichte über die Deutsche ophthalmologische Literatur.

Anatomie des Auges (II. Semester 1913). Von R. J. Sobotta

in Würzburg 276

Die angeborenen Anomalien und Mißbildungen des Auges

(II. Semester 1913). Aron R. Seefelder in Leipzig . . 287 Physiologie des Gesichtssinnes und der Augenbewegingen.

Von H. Köllner in Würzburg 373

Bericht über Mikroorganismen und Serologie (ausschließlich

serologische Diagnostik und Therapie). (I. Semester 1914.)

Von M. Zade in Heidelberg 29õ

SympathischeOphthalmie. (Bericht über die deutsche Literatur

des 1. Halbjahres 1914.) Von G. H. Sattler in Gießen . 302 Spezielle Pathologie und Therapie. (I.

u. II. Semester 1913.)

Von Konrad Schrader in Gera47, 159, 305

Untersuchungsmethoden (I. u. II. Semester 1913). Von

F. Dimmer in Wien 156

Berichte über die ausländische ophthalmologische Literatur.

HoUändische Literatur des Jahres 1914. I. Semester. Von

W. Koster-Gzn in Leiden und G. J. Sciioute in Amsterdam . 175 Bericht über die italienische

Literatur des Jahres 1913. Von

Speciale-Cirincione in Rom 407, 455

Bericht über die russische ophthalmologische Literatur.

(II. Semester 1913.) Von Th. Werncke in Odessa . . . 388 Ungarische Literatur der Jahre 1911,

1912, 1913. Von Ludw.

Vermes in Budapest 67

Gesellschafts-Beriehte.

Berliner ophthalmologische Gesellschaft. Sitzung vom 21. Mai,

25. Juni und 23. Juli $1914 \quad 79.328$

Vereinigung hessischer und hessisch-nassauischer Augenärzte.

Sitzung vom 3. Mai $1914 \quad 180$

Gesellschaft der Augenärzte in Moskau. Sitzung vom 29/ April

(12. Mai) $1914 \quad 193$

St. Petersburger ophthalmologische Gesellschaft. Sitzung vom

13. Februar und 27. März $1914 \quad 78$

Wiener ophthalmologische Gesellschaft. Sitzung vom 11. Mai,

25. Mai und 15. Juni 1914184

Unfall- und Versicherungskunde 80, 194

Diagnostische Referate $\quad 84,198$

Therapeutische Umschau $\quad 86,199,475$

Buchanzeigen 332, 478

Literatur $\quad 90,335,417,479$

Berichtigung 204 
Tagesnachrichten und Personalien .... 92, 204, 340, 420, 482

Karl Völckers $\dagger \ldots 92$

Sachregister 483

N. Namenregister .490

Titel und Inhaltsverzeichnis zu Bd. XXXII. 